\title{
CELDAS METÁLICAS DE MEDIA TENSIÓN APTAS PARA SOPORTAR ARCO INTERNO
}

Ing. Claudio Enrique Cendra $\left(^{*}\right)$

$T$ as actuales instalaciones eléctricas, están Lincorporando, cada vez, con mayor exigencia, el cumplimiento de medidas de seguridad para los operadores. Las Celdas Primarias construidas de acuerdo a IEC62271-200 brindan seguridad para los operadores, en condiciones de cortocircuito.

Básicamente una Celda de Media Tensión es un dispositivo de maniobra, contenido en una envolvente metálica, preparado para conectar y desconectar instalaciones, con tensiones nominales mayores a $1 \mathrm{kV}$.

En Argentina las tensiones normales de distribución disponemos de redes en $13,2 \mathrm{kV}$ y $33 \mathrm{kV}$, existiendo además aplicaciones especiales con tensiones intermedias.

Una celda primaria está preparada para operar como primer escalón ante una falla, por lo tanto los valores de corrientes de cortocircuito que debe despejar son mayores. Dado que es el primer elemento de corte disponible entre el generador y la carga.

Existen en nuestro país al menos tres fabricantes de celdas de éste tipo. Donde uno de los requisitos de mayor importancia es garantizar la seguridad de las personas involucradas en la operación.
La IEC 62271-200 es una norma internacional que define las características que debe cumplir una celda de media tensión para soportar cortocircuitos internos, en sistemas de tensiones nominales comprendidas entre $1 \mathrm{kV}$ y $52 \mathrm{kV}$.

La evolución de esta reglamentación es la siguiente:

Año 1969 IEC 298

Año 1985 (Junio) IRAM 2200 primera edición argentina

Año 1990 IEC 60298

Año 2003 (Nov.) IEC 62271-200

Año 2004 (Febr.) EN 62271-200

Año 2011 (Oct.) IEC 62271-200 Edición 2.0

El aspecto fundamental, es definir una serie de requisitos a cumplir por la envolvente metálica exterior, de manera que ante la ocurrencia de una falla (cortocircuito) en su interior, la sobrepresión, calor y los gases producidos puedan ser eliminados sin generar perjuicio a personas que puedan estar en las cercanías.

(*) CLAUDIO ENRIQUE CENDRA - Ingeniero Electricista con Orientación Industrial - Gerente de Energía de Proyección Electroluz S.R.L. Reconquista - Santa Fe - Docente U.T.N. Facultad Regional Reconquista - Santa Fe 
En toda celda metálica se definen al menos cuatro (4) compartimientos perfectamente diferenciados:

Cúbico de baja tensión: donde se alojan elementos de protección, señalización y comando, borneras de conexión, interruptores termo magnéticos y otros elementos necesarios para el control. Éste es el único espacio accesible por un operador cuando la celda se encuentra tensionada, donde los riesgos son limitados. Los demás compartimientos, cuando la celda esta energizada, permanecen bloqueados. diferentes celdas que componen un centro de distribución.

Cúbico de acometida de cables: generalmente en la parte inferior posterior, y es el espacio destinado a las conexiones externas de la celda con el sistema de potencia

La norma es clara en cuanto a los ensayos que se deben realizar para garantizar el comportamiento de la envolvente frente a un cortocircuito. En toda Latinoamérica existe un único laboratorio ubicado en Brasil, CEPEL, con el equipamiento necesario

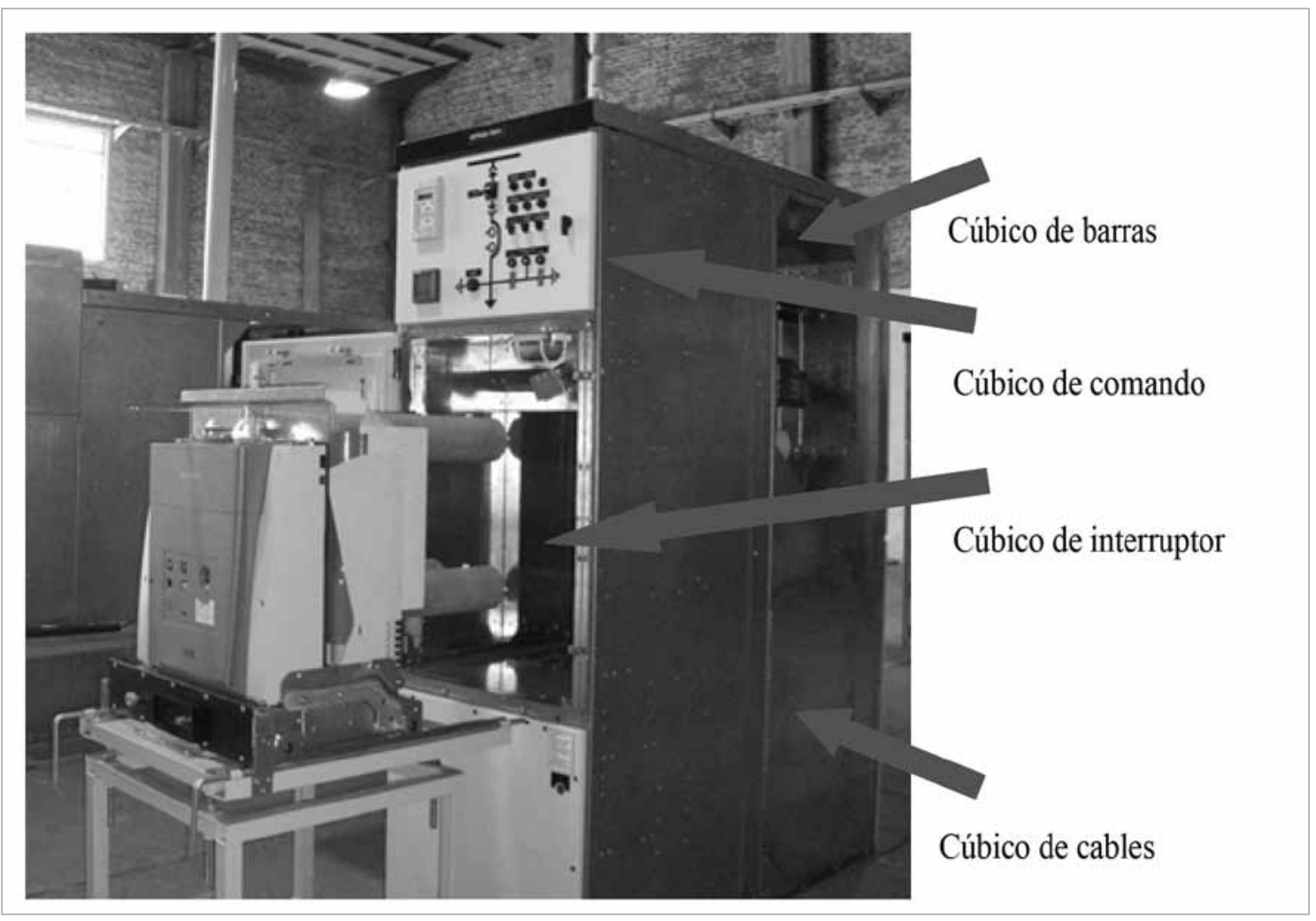

Cúbico de interruptor: donde se aloja el interruptor de potencia con sus conexiones posteriores que se vinculan en la parte superior al compartimiento de barras y por la parte inferior al compartimiento de cables.

Cúbico de barras: espacio destinado a las barras de potencia que conectan entre sí, las para realizar estos ensayos.

La prueba consiste en realizar tres cortocircuitos, utilizando alambres calibrados que se fundan en un determinado tiempo. Estos cortocircuitos se realizan a tensión nominal primeramente en el cúbico de cables, luego en el de barras y finalmente en el 


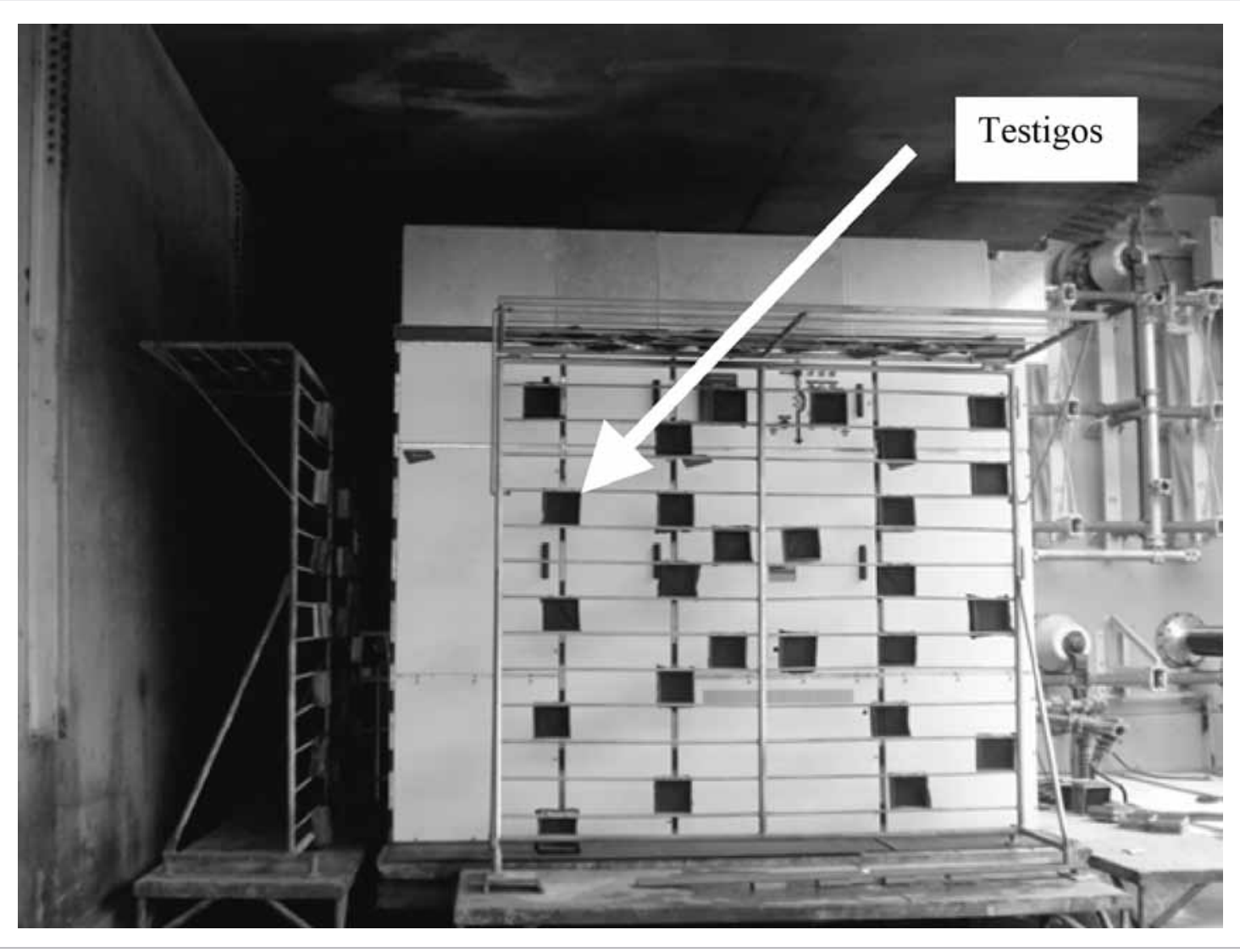

de interruptor. Sobre un prototipo completamente equipado, ubicando a cada lado del mismo, dos celdas de iguales características, y colocando en el exterior testigos de tela de algodón, en el frente, arriba y detrás de la celda.

Con posterioridad al ensayo se deben verificar los siguientes aspectos:

1. No se deben abrir las puertas o tapas de la celda ensayada

2. No se deben proyectar al exterior partes que puedan representar peligro para una persona

3. No se deben producir aberturas o perforaciones de la envolvente metálica

4. Ninguno de los testigos indicadores verticales ni horizontales debe encender
5. El sistema de puesta a tierra debe mantener su efectividad después del ensayo.

Proyección Electroluz SRL realizó el primer ensayo en CEPEL en 2004 con los siguientes resultados:

Celda de 13,2kV - Umax $15 \mathrm{kV}$ - Inom 1250A- Icc $25 \mathrm{kA}-1 \mathrm{seg}$. Celda de $33 \mathrm{kV}$ - Umax $36 \mathrm{kV}$ - Inom 1250A - Icc 16kA -1 seg.

En 2010 se repitieron los ensayos ampliando los niveles de cortocircuito a los siguientes valores:

Celda de 13,2kV- Umax $15 \mathrm{kV}$-Inom 1250A - Icc $31,5 \mathrm{kA}-1 \mathrm{seg}$. - Inom $2500 \mathrm{~A}$ - Icc $31,5 \mathrm{kA}-1 \mathrm{seg}$.

Celda de $33 \mathrm{kV}$ - Umax $36 \mathrm{kV}$ - Inom 1250A - Icc 20kA - 1seg.

En ambas oportunidades los resultados han sido satisfactorios. Permitiendo ingresar al mercado un número importante de unidades que están en servicio en diferentes puntos del país. 
El resumen es el siguiente:

\begin{tabular}{|c|c|c|c|c|}
\hline $\boldsymbol{A} \tilde{\boldsymbol{n}} \boldsymbol{0}$ & $\mathbf{6 , 6} \boldsymbol{k}$ & $\mathbf{1 3 , 2} \boldsymbol{k} \boldsymbol{2}$ & $\mathbf{2 4 k} \boldsymbol{k}$ & $\mathbf{3 3 \boldsymbol { k }}$ \\
\hline 2004 & 11 & 3 & 0 & 9 \\
\hline 2005 & 0 & 18 & 0 & 6 \\
\hline 2006 & 0 & 73 & 0 & 1 \\
\hline 2007 & 0 & 6 & 0 & 7 \\
\hline 2008 & 0 & 11 & 0 & 13 \\
\hline 2009 & 8 & 4 & 0 & 17 \\
\hline 2010 & 0 & 90 & 0 & 38 \\
\hline 2011 & 0 & 37 & 0 & 92 \\
\hline 2012 & 9 & 99 & 22 & 22 \\
\hline 2013 & 0 & 57 & 0 & 39 \\
\hline 2014 & 0 & 13 & 0 & 6 \\
\hline Total & $\mathbf{2 8}$ & $\mathbf{4 1 1}$ & $\mathbf{2 2}$ & $\mathbf{2 5 0}$ \\
\hline
\end{tabular}

$\checkmark$ Medición de resistencia de contacto

$\square$ Inyección primaria de corriente y verificación de medidores y protecciones

$\checkmark$ Tensión resistida a frecuencia industrial

$\checkmark$ Intercambiabilidad de interruptores

Emitiendo los Protocolos de En-

Un aspecto importante para destacar es que toda la ingeniería de desarrollo es propia, se han completado otros ensayos en laboratorios oficiales del país, como: corriente de breve duración, impulso, tensión resistida a frecuencia industrial, calentamiento, etc. para garantizar la confiabilidad del diseño y cumplir con todos los ensayos de tipo necesarios.

Además el diseño cumple con todas las condiciones de enclavamiento y seguridad para la operación confiable.

Desde 2009, Proyección Electroluz SRL y la Universidad Tecnológica Nacional, como parte del convenio de co-participación firmado oportunamente, han establecido que todo el Control de Calidad de los productos elaborados, lo realice personal de la Facultad Regional Reconquista. Por lo tanto un ingeniero egresado de dicha facultad, conjuntamente con un grupo de alumnos próximos a terminar la carrera, son los responsables de realizar todos los ensayos de rutina:

$\checkmark \quad$ Verificaciones dimensionales

$\checkmark \quad$ Verificaciones mecánica y eléctricas sayo correspondientes de manera de garantizar al cliente final la calidad de los productos. Esto se hace no solo con las celdas de media tensión, sino con todos los productos de fabricación.

Además de esto, todos los alumnos de la facultad pueden realizar diferentes prácticas en las instalaciones de la Empresa, utilizando equipamiento de última generación $\mathrm{y}$ trabajando sobre gabinetes, tableros y celdas reales.

La interacción Empresa - Facultad es positiva y nos está permitiendo formar a los nuevos profesionales con un valor agregado que no en todas las facultades es posible.

Esta integración que ambos se beneficien con el intercambio de conocimientos y experiencias, y logra una inserción del nuevo profesional en el medio mucho más ágil. 